\title{
UM NOVO PARADIGMA DOS CONTRATOS?
}

\author{
Eros Roberto Grau \\ Professor Titular da Faculdade de Direito da \\ Universidade de São Paulo*
}

\begin{abstract}
Resumo:
Uma análise do instituto dos contratos como, por exemplo, os celebrados com consumidores e que todavia não pode ser concebido como novidade no campo das relações contratuais. $\mathrm{O}$ autor não procura reconstruir a teoria geral do contrato, mas, sim, reconstruir teorias que expliquem uma realidade social inteiramente renovada. Eé a consciência desse fato que deve ser o pressuposto da interpretação contratual.
\end{abstract}

\begin{abstract}
:
One analyzes of the institute of contracts as, for example, the celebrated ones with consumer and that however it cannot be conceived as new development in the field of the contractual relations. The author does not look for to reconstruct the general theory of contracts, but yes, to reconstruct theories that explain a social reality entirely renewed. And is the conscience of this fact that must be the estimated one of the contractual interpretation.
\end{abstract}

Unitermos: teoria geral dos contratos; relações contratuais; interpretação contratual.

Neste início de século, quando tratamos da teoria geral dos contratos, ressentimo-nos da falta de pontos de partida seguros, de premissas básicas e claras para a compreensão desse "instituto". Isso sempre acontece, é bem verdade, nas searas onde, há muitos séculos, a doutrina vem sedimentando extratos, um sobre o outro, para a construção da chamada "base teórica" Cada uma dessas camadas representa uma

* Professor visitante da Faculdade de Direito da Universidade de Montpellier I , França, no período de 1995 a 1998. 
evolução e, na grande maioria das vezes, há uma profunda resistência em admitir que a anterior está superada. Na passagem dos extratos, é natural abandonar os pontos de partida daqueles que nos antecederam.

Mais difícil é aceitar que o novo e o antigo se mesclam e, no resultado geral, as fronteiras de um extrato são fluidas, impossibilitando a confortável ilusão da segurança jurídica.

Grande parte dos desencontros doutrinários sobre o moderno contrato deriva do esquecimento de uma premissa básica que o intérprete (autêntico ou-não) deveria, necessariamente, ter em mente: todo contrato instrumenta a jurisdicização de uma ou mais relações negociais travadas entre as partes que dele participam e por ele se obrigam. O vínculo Contratual (vínculo jurídico) instala uma situação de certeza e segurança juridicas para as partes. Vale dizer: cada parte tem a aparente certeza e a segurança que dele deflui, de que, na hipótese de descumprimento do contrato, poderá recorrer a meios jurídicos adequados à obtenção de reparação por esse descumprimento, ou mesmo a execução coativa da avença. ' Inegável que essa premissa básica contamina todos os contratos, sejam administrativos, empresariais, trabalhistas ou com consumidores.

Ademais, há de se admitir que ninguém contrata pelo mero prazer de trocar declarações de vontade, como já se disse. Da mesma forma, as partes somente contratam se acreditarem que a vinculação lhes será afinal vantajosa, como os economistas especializados em organização industrial têm nos mostrado.

Tenho que essa situação de certeza e de segurança é um dos motores principais que leva as partes a buscarem o vínculo Contratual e, principalmente, $o$ ordenamento jurídico a tutelá-lo. ${ }^{2}$

A conclusão que surge, então, é inexorável: se o Direito presta-se a organizar, administrar e harmonizar conflitos, a jurisdicização dos contratos viabiliza

1. Não posso deixar de notar que, infelizmente, nossa Jurisprudência, às vezes, se esmera em fazer ruir esse pressuposto de certeza e segurança, intervindo eın contratos privados entre agentes econômicos que nada têın de hipossuficientes. A autonomia da vontade, que deveria ser a regra, é indevidamente substituída pelo entendimento que o julgador passa a ter do negócio. Passa o Judiciário, então, a ignorar o pressuposto básico da racionalidade dos agentes econômicos, arvorando-se a condição de protetor daqueles que tinhain plenas condições de contratar e se obrigar em igualdade de condições.

2. Por óbvio, como veremos adiante, um contrato celebrado entre duas sociedades de grande porte em muito difere daquele celebrado entre fornecedor e consumidor. No primeiro caso, as partes, quando firmam o instrumento Contratual, buscam conscientemente a vinculação. No segundo, na maioria dos casos, o consumidor quer, apenas, comprar e o fornecedor vender - é o ordenamento que atribui ao ato (fato) da compra consequệncias jurídicas, tutelando o vínculo que se faz estabelecer. Em ambas as hipóteses, todavia, o sistema funciona para garantir o comércio, a segurança no tráfico. 
a funcionalidade do Direito, porque traduz segurança e previsibilidade, porque possibilita a fluência das relações de mercado.

É corrente a afirmação de que houve alteração nos paradigmas tradicionais do contrato, o que atribui, a quem o afirme, certificado de cultura: desde o início dos anos 80 , está na moda a alusão a paradigma. E a essa primeira afirmação segue a da necessidade de construção de um novo paradigma de contrato. No final dos anos 90, mais do que nunca, essa premência é anunciada com bulha nas academias, pois o e-commerce exigiria urgentemente um novo paradigma de contrato.

O observador atento, contudo, diante dessa sentença, auctoritas ditada a falsa auctoritas, fundada no uso de uma linguagem que tanto mais impressiona quanto mais hermética - indagará de qual contrato se cuida.

Pois é certo que o contrato não é um instituto único, porém um feixe de institutos jurídicos (os contratos), assim como a propriedade, também, é um feixe de propriedades.

O paradigma dos contratos praticados sob as normas da "lex mercatoria" não é, por certo, o mesmo paradigma dos contratos, cujo conteúdo é uniformizado por meio de condições gerais. O regime jurídico do contrato de trabalho é, de há muito, inteiramente distinto daquele(s) aplicável(eis) à circulação de outra(s) mercadoria(s) que não o trabalho. De sorte que, à toda evidência, o caráter protetivo que marcaria os contratos celebrados com consumidores, em especial aqueles, cujo conteúdo é uniformizado por meio.de condições gerais, não pode ser concebido como uma novidade no campo das relações contratuais.

A questão da necessidade do novo paradigma toma mais corpo, quando se faz referência aos contratos celebrados com consumidores, mediante a imposição de condições gerais. Mas, quais princípios importa ponderarmos quando tratamos dessas avenças? Por que justamente aqui se afirma tão insistentemente a necessidade da construção de um novo paradigma de contrato?

A resposta a essas questões requer atenção: devemos ficar bem alertas ao fato de que atualmente não estamos, apenas, procurando reconstruir a teoria geral do contrato, mas sim reconstruir teorias que expliquem uma realidade social inteiramente renovada. A consciência desse fato deve ser o pressuposto da interpretação Contratual.

Nesse quadro, encontro justificativas para afirmar que certos adeptos da critical contract law, norte-americana, incorporam uma visão ingênua da realidade, limitando-se, em verdade, a produzir critica da doutrina juridica e a cogitar de princípios da doutrina - e não do Direito. 
O discurso a respeito da crise do contrato e da necessidade de um novo paradigma é desenrolado a partir da análise da teoria clássica do contrato.

Esse discurso, no entanto, em todas as suas versões, mas especialmente naquela produzida pelos norte-americanos, em sua origem desde quando se passa a falar na morte do contrato ${ }^{3}$ (Gilmore) é, na verdade, um discurso a favor da vida do contrato, na medida em que propõe a superação daquela teoria. $O$ mesmo se pode dizer em relação à queda da liberdade Contratual, clamando por uma nova teoria dos contratos, como já queria Atiyah no final dos anos $70 .{ }^{4} \mathrm{Em}$ todas essas exposições, mostra-se justamente o poder de sobrevivência do contrato, que continua embasando o sistema econômico na medida em que se transforma: declínio do dogma da vontade das partes, de um lado, ascensão dos "contratos fato", como veremos adiante. Mas, sempre e acima de tudo, avenças (= vínculos jurídicos) que proporcionam a fluência das relações de mercado.

À "morte do contrato" corresponde o fim da teoria clássica, que, na dicção de Guido Alpa, cede ante a necessidade da análise dos interesses concretos que o acordo entre as partes expressa, análise conduzida não segundo o método formal, mas mediante o exame dos interesses substanciais - ao que corresponde a objetivação e despersonalização do contrato.

Alpa" desenha dois modelos de aproximação do contrato:

a. um nele enfatiza o ato de autonomia privada, o negócio reservado às partes, no qual as intervenções externas (do juiz ou do legislador) devem ser consideradas atos de exceção e limitadas na sua abrangência; esta é a concepção do Direito Contratual fundada na santidade do contrato ("sacertà del contratto"; "sanctity of contract");

b. no outro visualiza o contrato, "fato" das partes, como ato exposto a todas as intervenções externas consentidas pelo ordenamento, "fato" que, portanto, pode ser "criado" pelo Poder Judiciário e pode ser esculpido de modo variado pelo

3. Vide Grant Gilmore. La morte del contratto, trad. de Cosimo Marco Mazzoni e Vincenzo Varano, Giuffrè Milano, Itália, 1988.

4. The rise and fall of freedom of contract, de P.S. Atiyah, Oxford, Clarendon Press, 1979.

5. Ensaio introdutório à tradução italiana do The Death of Contract, de Gilmore (La morte del contratto, trad. de Cosimo Marco Mazzoni e Vicenzo Varano, Giuffrè, Milano, 1988, p. XII).

6. Ob. cit., p. XV. 
legislador; esta é a = "versão moderna" do Direito Contratual, que decretou a "morte" do contrato, o retorno ao "status" a superação da "privatezza" do negócio.

A teoria clássica do contrato, observa Lawrence Friedman, ${ }^{7}$ é cega em relação aos detalhes da fattispecie e da pessoa; não pergunta quem compra e quem vende e que coisa é comprada ou vendida; o Direito dos Contratos é uma abstração, importando em uma voluntária renúncia ao particular, em um deliberado abandono da tentação de restringir-se a livre autonomia individual ou o mercado livre em nome de qualquer política pública.

A concepção do contrato como "encontro de vontades", cuja disciplina está fundada na liberdade das partes pressupõe a limitação da atuação do Poder Judiciário em relação a ele; o Judiciário não pode intervir para questionar o conteúdo do contrato, devendo se limitar a confrontar o comportamento das partes com o que a lei prescreve; em outras palavras: não pode fazer o contrato pelas partes. ${ }^{\circledR}$

Assim, vê-se para logo que a teoria clássica do contrato e o ideal do livre mercado andam entrelaçados, de mãos dadas. A teoria econômica do laissez faire, anota Gilmore" se reduz a algo assim: se todos nós fizermos exatamente aquilo que nos agrada, tudo certamente se resolverá pelo melhor. E prossegue: a isso parece corresponder, na prática, a teoria do contrato, quando a responsabilidade é reduzida ao minimo e inexistem sanções pelo inadimplemento do contrato; aqui, então, o "cada um por si e Deus por todos" 10

Mas, na medida em que o ordenamento jurídico atribui maior força vinculante ao contrato, porque impõe sanções para o seu descumprimento e passa a intervir para tutelar a parte pretensamente mais fraca, faz com que o contrato continue a desempenhar, exatamente, a mesma função que sempre lhe foi reservada. A objetivação e a despersonalização do contrato, como veremos adiante, embora signifiquem mudanças, em nada alteram sua essência e o papel que desempenha no sistema.

Os reflexos que decorrem da aproximação que Guido Alpa atrela à "versão moderna" do Direito Contratual, seja no plano dogmático, seja no que tange a efeitos produzidos sobre o plano prático, são evidentes.

7. Apud Gilmore, ob. cit., p.8.

8. Cf. ALPA, ob. cit., pp. XXI/XXII.

9. Ob. cit., p. 85 .

10. Idem, p.86 
Permito-me, a esse respeito, deter-me na consideração de três aspectos que, segundo me parece, desnudam inteiramente o sentido e significado do que a doutrina tem referido como objetivação e despersonalização do contrato.

O primeiro deles diz com a expansão do âmbito da responsabilidade, que, na teoria clássica do contrato, era estreitamente limitada. A consagração da responsabilidade objetiva, até a responsabilidade do produtor pelo fato do produto, associada à aplicação do princípio da vedação do enriquecimento sem causa - inclusive nas chamadas promessas de contrato - abala os pilares de sustentação da teoria.

O segundo aspecto que me permito ferir respeita à necessidade de sujeitarmos a rigorosa análise a noção de Direito subjetivo, que não se reduz à facultas agendi.

O Direito subjetivo, reafirme-se, é a permissão jurídica para o uso da facultas agendi. Permissão, do uso de faculdades humanas (faculdades que estão no homem, não no Direito), concedida por normas jurídicas." O Direito subjetivo, insisto, não é faculdade, mas permissão para o seu exercício. Assim, ser titular de um Direito subjetivo é estar autorizado pelo ordenamento jurídico a praticar, ou a não-praticar, um ato - isto é, a transformar em ato a potência. A transformação da faculdade em ato, quando juridicamente autorizada, somente pode ser exercida dentro dos limites da autorização.

Compreendê-lo parece-me indispensável ao discernimento de que, tanto no que respeita à propriedade, quanto no que concerne ao contrato, o Direito pode introduzir inúmeros requisitos para o exercício de certa faculdade (= elementos integrantes da autorização). Assim deve ser encarada a imposição de obrigações, deveres e ônus a serem suportados pelo titular do Direito subjetivo para que lhe seja autorizado o exercício desse mesmo Direito (o que, v.g., explica a imposição do dever de informar, art. $6^{\circ}$ III e parágrafo único do art. $8^{\circ}$ do Código de Defesa do Consumidor).

Por isso, o Direito subjetivo não é, definidamente, um atributo da vontade do individuo, senhor dele. Ignorar esse fato é ver como novo algo que, na realidade, há muito nos circunda.

O terceiro aspecto diz com o discernimento de que a interpretação do Direito envolve a criação da norma pelo intérprete autêntico, no sentido dessa expressão atribuída por Kelsen. ${ }^{12}$

11. Gofredo da Silva Telles Júnior. $O$ direito quântico, $5^{\text {a }}$ edição, Max Limonad, São Paulo, 1980, pp.395-398.

12. Hans Kelsen. Teoria pura do direito, trad. de João Baptista Machado, $4^{\mathrm{a}}$ edição, Arménio Amado Editor, Coimbra, 1979, pp 469 e ss. 
Interpretar é, além de compreender, reformular ou reexprimir o objeto da interpretação, sob forma nova. A interpretação, assim, consubstancia um processo intelectivo, através do qual, partindo de fórmulas lingüisticas contidas nos atos normativos, alcançamos a determinação do seu conteúdo normativo. Ai o caráter alográfico da interpretação do Direito.

O texto, preceito, enunciado normativo é alográfico, na medida em que não se completa no sentido nele impresso pelo legislador. A "completude" do texto somente é realizada quando o sentido por ele expressado é produzido, como nova forma de expressão, pelo intérprete. Mas o "sentido expressado pelo texto" já é algo novo, distinto do texto: é a norma. Isso significa que o texto normativo, visando a solução de conflitos ou litigios (isto é, uma decisão normativamente fundada para problemas práticos, em razão do que consubstancia dever-ser, reclama um intérprete "primeiro intérprete" que compreenda e reproduza, não para que um segundo intérprete apenas possa compreender, mas a fim de que um determinado conflito (litigio) seja decidido. Por esse motivo, a interpretação do Direito opera a mediação entre o caráter geral do texto normativo e sua aplicação particular: isto é, opera a sua inserção na vida.

A interpretação, pois, é um processo intelectivo mediante o qual, partindo de fórmulas lingüisticas contidas nos textos, enunciados, preceitos, disposições, alcançamos a determinação de um conteúdo normativo. O intérprete desvencilha a norma do seu invólucro (o texto); neste sentido, o intérprete "produz a norma". Assim, atividade que se presta a transformar disposições (textos, enunciados) em normas, a interpretação é meio de expressão dos conteúdos normativos das disposições, meio através do qual o intérprete desvenda as normas contidas nas disposições.

Isso quer dizer que o significado da norma é produzido pelo intérprete, mas não qualquer intérprete; apenas produz normas o "intérprete autêntico"

Aparecem de modo bem distinto, pois, o texto (a disposição) e a norma: a interpretação é meio de expressão dos conteúdos normativos das disposições, meio através do qual pesquisamos as normas contidas nas disposições. Logo, é atividade que se presta a transformar disposições em normas.

Isso, no entanto, não-significa que o intérprete, literalmente, crie a norma; o intérprete a expressa; o produto da interpretação é a norma expressada como tal; mas ela (a norma) preexiste, potencialmente, no invólucro do texto, invólucro do enunciado. A norma encontra-se, em estado de potência, involucrada no enunciado (texto ou disposição); o intérprete a desnuda; isto é, desvencilha a norma de seu invólucro, fazendo-a brotar do texto, do enunciado. Por isso digo que o intérprete "produz a norma" 
$\mathrm{Na}$ interpretação dos contratos clássicos, o texto não se encontra no Direito posto pelo Estado, porém no Direito posto pelas partes: o texto é o contrato. No segundo tipo de contrato referido por Alpa (contrato como "fato das partes"), o texto está sim no Direito posto pelo Estado e não naquele produzido pelos agentes econômicos. Eis uma profunda diferença a apartá-los.

Mas, tanto em um quanto em outro caso, as partes não exercitam livremente suas vontades. Fazem-no nos limites do Direito posto, mesmo porque, como vimos, o Direito subjetivo é a permissão jurídica para o uso da facultas agendi; ser titular de um Direito subjetivo é estar autorizado pelo ordenamento jurídico a praticar, ou a não-praticar, um ato; repito: a transformação da faculdade em ato, quando juridicamente autorizada - e apenas aí o Direito subjetivo - somente pode ser exercida dentro dos limites da autorização.

O juiz, intérprete autêntico, não se limita a confrontar o comportamento das partes com o que o Direito posto pelo Estado prescreve. É ele, o juiz, quem produz normas veiculadas ou pelas disposições contratuais ou pelo texto legal. Por mais que isso revolte a doutrina, a segurança e a previsibilidade dos contratos passa, necessariamente, pela interpretação que as Cortes dão às avenças. $O$ reconhecimento do crucial papel do Poder Judiciário talvez seja o início da superação de tantos entraves enfrentados pela ordem jurídica na promoção do comércio.

Após a consideração desses aspectos, devemos ferir o tema do estado atual do pensamento jurídico sobre os contratos, fazendo-o, como anunciado, criticamente.

Desde a segunda metade do século passado, o Direito dos Contratos é afetado por imposições da ordem pública: poder de polícia, a defesa dos bons costumes, imposições "protetivas" do Direito do Trabalho, a legislação antitruste, v.g. Essas intervenções prosseguem até a instalação do que se tem referido como a normatividade do Welfare State, ${ }^{13}$ afetando, marcadamente, a disciplina dos contratos.

Os contratos passam a ser apresentados menos como uma livre construção da vontade humana do que como contribuição da atividade dos agentes econômicos à arquitetura geral da economia definida pelo Estado contemporâneo. ${ }^{14}$ A doutrina elabora a noção de dirigismo Contratual, emerge o instituto dos contratos coativos.

13. Vide Elementos de Direito Econômico, Editora Revista dos Tribunais, São Paulo, 1981, pp 1.5 e ss. e $A$ ordem econômica na Constituição) de 1988 (interpreta̧̧ão e crítica), da autoria deste autor, $2^{3}$ edição, Editora Revista dos Tribunais, São Paulo, 1991, pp. 39 e ss.

14. René Savatier. Du Droit Civil au Droit Public, 2ª edição, LGDJ, Paris, 1950, p. 65. 
Estranhamente, parte dos nossos juristas reage a essa evolução - o que é mais estranho ainda - alguns especialistas do Direito Público. Recusa a noção de contrato coativo, que toma como um outro instituto, distinto do instituto do contrato. Essa parcela da nossa doutrina assim procede porque (a.) continua concebendo a noção de contrato no plano exclusivamente metafísico, abstrato, dissociado da realidade (contrato = encontro de vontades), ao mesmo tempo em que (b.) pensa o Direito subjetivo como uma faculdade. No entanto, na realidade, estamos vivendo um momento qualitativamente distinto da teoria geral do contrato.

Uma das lições maiores no livro de Gilmore ${ }^{15}$ encontra- se na citação de Corbin, para quem os juristas geralmente incidem nos erros de conceber o Direito como algo absoluto e eterno, de imaginar que as fórmulas doutrinárias possam ser usadas mecanicamente e de que sejam definições corretas e imutáveis; o professor, o advogado e o juiz, afirma, precisam libertar-se da ilusão da certeza. Ou, como disse acima, aceitar a superação e o amálgama dos extratos da evolução jurídica.

Na década dos 80 , no entanto, a consagração pelo Direito posto pelo Estado de preceitos voltados à proteção dos consumidores e do meio ambiente, opera no sentido de - excuso-me pelo galicismo - bouleversar a teoria do contrato.

Ambientalistas e consumeristas, no entusiasmo às vezes ingênuo que os nutre, de um lado ignoram que tanto o Direito do Consumidor quanto o Direito Ambiental visam a preservar o próprio sistema jurídico vigente, não havendo, na realidade, qualquer ponto de ruptura da teoria clássica do contrato. Não estamos diante de uma alavanca de transformação do mundo, como querem alguns.

É bem verdade que a desestruturação pela qual passa o chamado Estado moderno o transforma, mas ele ainda funciona como ente regulador, apto a expedir textos normativos vinculantes para os agentes econômicos. Em que direção, no entanto, deve ir essa regulação?

Consumeristas reclamam a intervenção do Estado nos contratos. Mas, indaga-se também, qual intervenção? Intervenção a favor de quem? Intervenção contra o que? Intervenção contra quem?

Penso que as respostas que se possa conferir a essas indagações apontam no sentido de que não há um novo intervencionismo no quadro das atuações estatais sobre os contratos, cujo conteúdo é uniformizado por meio de condições gerais. Aqui, mais uma vez, o Estado atua provendo a circulação mercantil e a fluência das relações 
de intercâmbio, de modo que dessa atuação não decorre qualquer mudança qualitativa a afetar o caráter do intervencionismo.

Por isso, podemos dizer que é necessário modernizar a teoria clássica do contrato - agora no que tange a suas referências aos contratos, cujo conteúdo $\dot{e}$ uniformizado por meio de condições gerais - para que tudo permaneça funcionando regularmente na economia de mercado, a circulação mercantil fluindo regularmente $e$ as relações de intercâmbio sendo praticadas regularmente.

O Direito, neste tema, continua cumprindo o seu duplo papel: viabilizando, e justificando, as relações que fluem, segundo as regras da economia de mercado e instrumentando o exercício, pelo Estado, de políticas públicas voltadas justamente à preservação do mercado.

Ao Estado, no cumprimento da intervenção nos contratos, permanecem atribuídas as funções de atuar como terceiro regulador e como terceiro árbitro. ${ }^{16}$

Voltando ao âmbito da atuação estatal, resta indagarmos, pois, quais os princípios que devem informá-la e conformá-la, bem como identificar o objetivo final por ela visado.

No plano individual, dentro do quadro das relações contratuais, a proteção devotada pelo novo paradigma de contrato aos consumidores é, nitidamente, proteção da parte que detém menor força negocial. Não se nega, é evidente, que a massificação da produção e do consumo reclama o controle, pelo Estado, do poder normativo privado que entidades de classe ou setoriais exercem, produzindo Direito posto "privado", impondo sua vontade a partes débeis, fragilizadas. Isso, contudo, não consubstancia nenhuma mudança qualitativa, distinta daquela que afetou a teoria geral do contrato, quando a impactou a normatividade do Welfare State. ${ }^{17}$

Os consumidores são protegidos não por solidariedade, como querem

16. A maior prova desse fato está na atual perplexidade mundial face ao fenômeno do $\mathcal{c}$-commicice. Por um lado, deve-se proteger o consumidor. Mas - comno primeiramente perceberam os americanos - a proteção não pode ser tal que iniba o desenvolvimento desse tipo de comércio. Onde os direitos colocarão a virtude do meio termo? Como será tratada a extraterritorialidade de tantos direitos nacionais? Essas são questões em aberto que a realidade ainda não nos autoriza a responder.

O mesmo raciocínio informa a atual discussão sobre a proteção dos direitos dos acionistas ininoritários nas sociedades anônimas abertas. Ora, sua proteção tem o nítido e declarado escopo de atrair o capital para esse mercado e qualquer regra de proteção encontrará aqui seu limite.

17. Permito-me lembrar, neste passo, a legislação referente à limitação de juros e ao tabelamento de preços, bem assim a atinente ao inquilinato. Ademais, a respeito da concordata, não se perca de vista a fundamentação da conveniência de se manter atuantes no inercado o maior número possível de agentes econômicos. 
alguns; vale dizer: a proteção de que gozam não é produto de sentimento de solidariedade, porém expressiva de uma estratégia para a promoção da fluência do mercado.

Por tudo isso, digo que não existe e não deve ser perseguido um "novo paradigma de contrato". O contrato segue e sempre seguirá viabilizando a fluência das relações de mercado e, somente enquanto atender a essa função (e apenas nessa justa medida), a proteção do consumidor (ou do hipossuficiente) encontrará abrigo no sistema jurídico. Os limites são claros e inegáveis, embora possamos lastimá-los.

São Paulo, janeiro de 2001. 